Reprod. Nutr. Dévelop., 1986, 26 (1 B), 391-392.

\title{
Influence de la photopériode et des apports énergétiques pendant la gestation sur les taux plasmatiques de la prolactine, de l'hormone de croissance et de l'hormone placentaire lactogène puis sur la production laitière de la brebis traite
}

\author{
A. PERIER, F. BOCQUIER $(*)$, G. KANN, J. MARTINET
}

Département de Physiologie animale, I.N.R.A, 78350 Jouy-en-Josas, France.

(*) Département de l'E/evage et de Nutrition des Herbivores, I.N.R.A., Theix, 63122 Ceyrat.

Summary. During pregnancy long photoperiod increased plasma oPRL and oGH levels but had no effect on oPL levels. Energy intake did not alter these three hormone levels. With the same food intake during lactation, long photoperiod (15 h $30 \mathrm{~L}$ vs $8 \mathrm{~h} 30 \mathrm{~L}$ ) increased milk production. Body reserves at lambing had a significant effect on milk production and composition under long days but no effect under short days.

L'allongement de la durée d'éclairement (15 h 30 au lieu de 8 h 30) en fin de gestation et en lactation entraîne une augmentation de la production laitière associée à une augmentation de la sécrétion de prolactine (Bocquier, 1985). Cette influence passe par une orientation de l'énergie vers la production laitière au détriment des réserves corporelles. Nous avons examiné l'influence du niveau des réserves corporelles à la mise bas sur cette partition de l'énergie selen la photopériode.

Matériel et méthodes. Quarante-huit brebis Préalpes du Sud sont réparties (en tenant compte des productions laitières antérieures et des poids vifs) dans un dispositif factoriel $2 \times 2$ : le facteur photopériode $(15 \mathrm{~h} 30$ ou $8 \mathrm{~h} 30$ d'éclairement quotidien) appliqué à partir du $90^{\circ}$ jour de gestation est maintenu pendant la lactation. Le facteur apport énergétique $(115$ ou $85 \%$ des besoins définis par I'I.N.R.A, Tissier et Thériez, 1978) est appliqué depuis le $40^{e}$ jour de gestation jusqu'à la mise bas. Les brebis sont alimentées par lots de 12 animaux et les rations sont iso-azotées. Pendant la lactation, les brebis sont traites et reçoivent une ration identique couvrant largement les besoins. La composition corporelle des brebis à la parturition est estimée par la mesure de l'espace de diffusion de l'eau lourde (Bocquier et Thériez, 1984). Des échantillons sanguins sont prélevés toutes les heures pendant $25 \mathrm{~h}$ au $120^{\mathrm{e}}$ jour de gestation, et toutes les deux heures au cours des dernières $48 \mathrm{~h}$ de gestation. Les taux plasmatiques hormonaux sont mesurés à l'aide de dosages radio-immunologiques pour la prolactine (oPRL) et I'hormone de croissance (oGH), à l'aide d'un dosage radiorécepteur pour l'hormone placentaire lactogène (oPL).

Résultats et discussion. Les taux plasmatiques de PRL sont toujours significativement plus élevés chez les brebis en jours longs (tabl. 1). L'accroissement du taux de $\mathrm{GH}$ est marqué par de grandes variations entre individus mais devient significatif $(P<0,05)$ quand on tient compte des taux observés avant le début du traitement photopériodique. Le taux d'oPL n'est pas modifié par la photopériode.

Reproduction, Nutrition, Développement, $n^{\circ} 1$ B-86. -18 
Une augmentation du niveau des apports énergétiques en gestation n'a pas d'influence significative sur les taux des trois hormones ; elle accroît significativement la quantité de lipides corporels des brebis indépendamment de la photopériode.

La production laitière des brebis est significativement plus élevée en jours longs qu'en jours courts (tabl. 1). Les brebis grasses produisent plus de lait et de lipides que les brebis maigres en jours longs mais pas en jours courts.

TABL. 1. - Influence de la photopériode et du niveau des apports énergétiques pendant la gestation, sur la quantité de lipides corporels à la mise bas, la production laitière et les taux plasmatiques de certaines hormones.

\begin{tabular}{|c|c|c|c|c|c|c|}
\hline \multirow{2}{*}{$\begin{array}{c}\text { Photopériode } \\
\text { Energie }\end{array}$} & \multicolumn{2}{|c|}{ Courte } & \multicolumn{2}{|c|}{ Longue } & \multicolumn{2}{|c|}{ Effets du facteur } \\
\hline & Bas & Haut & Bas & Haut & Photopériode & Energie \\
\hline $\begin{array}{l}\text { Nombre de brebis } \\
\text { Lipides corporels }(\mathrm{kg}) \\
\text { Production laitière }(\mathrm{g} / \mathrm{j}) \\
\text { Production de lipides }(\mathrm{g} / \mathrm{j})\end{array}$ & $\begin{array}{r}10 \\
11,4 \\
883,2 \\
52,9\end{array}$ & $\begin{array}{r}12 \\
14,1 \\
892,3 \\
52,6\end{array}$ & $\begin{array}{r}12 \\
10,9 \\
1091,9 \\
65,6\end{array}$ & $\begin{array}{r}12 \\
14,4 \\
1278,2 \\
84,7\end{array}$ & $\begin{array}{l}\mathrm{ns} \\
* \\
*\end{array}$ & $\begin{array}{l}* \\
\text { ns } \\
\text { ns }\end{array}$ \\
\hline $\begin{array}{l}\text { au } 120^{\text {e }} \text { jour de gestation : } \\
\text { Nombre de brebis } \\
\text { oPRL (ng } / \mathrm{ml}) \\
\text { oGH (ng } / \mathrm{ml}) \\
\text { oPL (ng } / \mathrm{ml})\end{array}$ & $\begin{array}{r}12 \\
39,1 \\
10,2 \\
1097,3\end{array}$ & $\begin{array}{r}12 \\
41,7 \\
4,7 \\
825,0\end{array}$ & $\begin{array}{r}12 \\
354,6 \\
9,2 \\
985,2\end{array}$ & $\begin{array}{r}12 \\
511,9 \\
11,8 \\
874,4\end{array}$ & $\stackrel{*}{*}+\underset{n s}{*}$ & $\begin{array}{l}\text { ns } \\
\text { ns } \\
\text { ns }\end{array}$ \\
\hline $\begin{array}{l}\text { à la parturition : } \\
\text { Nombre de brebis } \\
\text { oPRL (ng } / \mathrm{ml})\end{array}$ & $\begin{array}{c}7 \\
1002,1\end{array}$ & $\begin{array}{c}7 \\
1102,7\end{array}$ & $\begin{array}{c}7 \\
1881,1\end{array}$ & $\begin{array}{c}7 \\
1987,2\end{array}$ & $* *$ & ns \\
\hline
\end{tabular}

La photopériode longue accroît la quantité d'énergie exportée par le lait, ce qui confirme et complète les résultats de Bocquier (1985). L'action favorable de la photopériode longue n'est significative que si les brebis disposent de réserves corporelles suffisantes au début de la lactation.

Bocquier F., 1985. Influence de la photopériode et de la température ambiante sur certains équilibres hormonaux et sur les performances zootechniques de la brebis en gestation et en lactation. Th. Doct.-Ing., INA - PG, 105 p.

Bocquier F., Thériez M., 1984. Prediction of ewe body composition at different physiological states, 152-157. In Lister D., In vivo measurement of body composition in meat animals. Elsevier, London.

Tissier M., Thériez M., 1978. Ovins, 403-449 dans Alimentation des ruminants. I.N.R.A. Publ. Versailles. 